\title{
O Uso da História da Química no Ensino de Química: A Visão de Licenciandos em Química
}

\section{Resumo}

A História da Química (HQ) tem sido considerada um recurso para as aulas de Química no Brasil, porém muitos professores e licenciandos dizem não terem capacitação ou interesse para incorpora-la à prática docente, criando um paradoxo. Com isso surgem alguns questionamentos: A HQ é importante para formar o professor? E para os estudantes da Educação Básica? Assim, surgiu o presente trabalho, com o objetivo de identificar a importância que licenciandos em Química de uma universidade federal, que cursavam a disciplina História da Química no ano de 2016 dão à disciplina, observando o que entendem pelo tema, quão importante é para sua formação e para o ensino de Química e como eles acham conveniente incorpora-la à prática. Baseados em estudos e nos documentos oficiais, buscou-se entender a importância que dão para a $H Q$ na formação do profissional e do aluno de Ensino Médio. Para isso, foi feito um acompanhamento das aulas da turma durante todo o curso, observando as aulas e as atividades realizadas por eles.

Palavras-chave: História da Química; ensino de Química; pesquisa com alunos.

\begin{abstract}
The History of Chemistry $(\mathrm{HC})$ has been considered a resource for chemistry classes in Brazil, but many teachers and graduates say they lack the capacity or interest to incorporate it into teaching practice, creating a paradox. With this come some questions: Is the HC important to train the teacher? And for the students of Basic Education? Thus, the present paper, with the objective of identifying the importance that graduates in Chemistry of a federal university, who studied the discipline History of Chemistry in the year of 2016 give to the discipline, observing what they understand by the subject, how important it is for their training and for the teaching of Chemistry and how they find it convenient to incorporate it into practice. Based on studies and official documents, it was sought to understand the importance they give to the $\mathrm{HC}$ in the formation of the professional and the student of High School. For this, it was made a follow-up of the classes of the class throughout the course, observing the classes and the activities carried out by them.
\end{abstract}

Keywords: History of Chemistry; Chemistry Education; research with students.

\section{INTRODUÇÃO}

Uma observação cuidadosa dos documentos que regem/regeram os conteúdos estudados nas aulas de Química no Ensino Médio revela a importância do contexto histórico. Os Parâmetros Curriculares Nacionais (PCN) para o Ensino de Química (EQ), por exemplo, trazem um discurso de que o conhecimento químico não é algo que deva ser entendido (e, portanto, não deve ser apresentado também) 
como um conjunto de ideias prontas e acabadas ${ }^{1}$, mas sim como uma construção da mente humana, em contínua mudança. É neste momento que a História da Química (HQ) aparece, sendo citada como parte do conhecimento socialmente produzido e sendo necessário que ela permeie todas as etapas do $E Q$, para possibilitar aos alunos esta compreensão do processo de elaboração do conhecimento químico, "com seus avanços, erros e conflitos"2. Dessa forma, podemos considerar que a HQ pode contribuir para a compreensão de um conceito científico e a própria natureza da ciência, além de deixar as aulas de Química mais interessantes e desafiadoras.

Nas Orientações Complementares ao PCN (PCN+), é possível observar a compreensão e 0 domínio da contextualização sociocultural como uma "inserção do conhecimento disciplinar nos diferentes setores da sociedade, suas relações com os aspectos políticos, econômicos e sociais de cada época e com a tecnologia e cultura contemporâneas"3. Este ponto revela uma importância para o uso de HQ nas aulas de Química (e, consequentemente, sua necessidade nas grades dos cursos de licenciatura em Química), uma vez que a História da Ciência (HC) "é o estudo das formas de elaboração, transformação e transmissão de conhecimentos sobre a natureza, as técnicas e a sociedade em diferentes épocas e culturas"4. Além disso, como apontado por Acevedo-Díaz, García-Carmona e Aragão5, a HC já se mostrou como um recurso bastante adequado para se ensinar sobre a natureza da Ciência, uma vez que "a História da Ciência mostra de maneira explícita os aspectos da natureza da Ciência e permite uma reflexão crítica sobre eles".

Em contrapartida ao observado nos documentos, é também notável que muitos professores não possuem capacitação ou interesse para o uso da $\mathrm{HQ}$ nas suas aulas, o que é citado em alguns estudos que falam do assunto, como os de Callegario e colaboradores ${ }^{6}$ e Barp ${ }^{7}$. Diante desse panorama, surgem as questões: $A \mathrm{HQ}$ realmente é importante para a formação dos licenciados? Qual a importância disso para as aulas da Educação Básica? Será que é realmente importante para jovens de 18 anos, que vão sair da escola e seguirão diferentes caminhos em suas vidas, terem em sua formação um aspecto histórico da Química? Assim surgiu o objetivo deste trabalho, que foi identificar essa importância, tão

\footnotetext{
${ }^{1}$ Brasil. Ministério da Educação. Secretaria de Educação Média e Tecnológica. Parâmetros Curriculares Nacionais - Ensino Médio (Brasília, 2000), p. 31.

2 Ibid.

3 Brasil. Ministério da Educação. Secretaria de Educação Média e Tecnológica. Orientações Educacionais Complementares aos Parâmetros Curriculares Nacionais - PCN+ Ensino Médio - Ciências da Natureza, Matemática e Suas Tecnologias. (Brasília, 2002), p. 88-89.

${ }^{4}$ Maria H. R. Beltran et al. História da Ciência para formação de professores (São Paulo: Livraria da Física, 2014), p. 5.

5 José A. Acevedo-Díaz, Antonio García-Carmona \& María del Mar Aragão. "Historia de la ciencia para enseñar naturaleza de la ciencia: una estrategia para la formación inicial del profesorado de ciencia", Educación Química 28, (2017): 141.

${ }^{6}$ L. J. Callegario et al. "História da Ciência no Ensino de Química: Uma Revisão", Revista Virtual de Química 7, no 3 (2015)

7 Ediana Barp, "Contribuições da História da Ciência para o Ensino da Química: Uma Proposta para Trabalhar o Tópico Radioatividade", in Anais do IV Jornada de História da Ciência e Ensino: propostas, tendências e construção de interfaces (São Paulo, Brasil, 2013).
} 
citada em documentos, também nas concepções de licenciandos em Química. Assim, durante o segundo semestre de 2016 foi feito um acompanhamento de uma turma que cursava a disciplina História da Química em uma universidade federal em Minas Gerais ${ }^{8}$, observando suas visões acerca do tema em dois aspectos: $1^{\circ}$ a necessidade da $H Q$ para a pessoa - licenciando, futuro docente e $2^{\circ}$ a necessidade da $H Q$ para a formação e atividade docente (onde entra a importância para o Ensino Médio).

\section{FUNDAMENTAÇÃo TEÓRICA}

A HC se firmou nos últimos anos como parte importante da formação dos profissionais da área. No tocante à formação em Química, tanto bacharelado quanto licenciatura, ela se torna importante para a formação de profissionais capazes de "questionar situações, sistematizar problemas e buscar criativamente soluções" . Ela se mostra ainda mais importante na Licenciatura, uma vez que vários documentos relativos à formação de professores de Química e ao EQ na educação básica apresentam, em suas listagens de objetivos e de competências, algum tópico relacionado à $H Q$, como os $P C N$ e os $\mathrm{PCN}+$.

\subsection{A História da Química em currículos nacional e estrangeiros}

Dentre as qualidades que as Diretrizes Nacionais para os Cursos de Química colocam como fundamentais para um licenciado ou bacharel em Química encontra-se a capacidade de "reconhecer a Química como uma construção humana e compreender os aspectos históricos de sua produção e suas relações com os contextos culturais, socioeconômico e político"10. Quando a discussão segue para a formação pessoal dos licenciados, afirmam que estes devem possuir "uma visão crítica com relação ao papel social da Ciência e à sua natureza epistemológica, compreendendo o processo histórico-social de sua construção"11. Apesar disso, em nenhum ponto da lista dos conteúdos básicos para a formação do licenciado há História da Química (em específico), História da Ciência (mais geral) ou qualquer outro conteúdo que pudesse ajudar no desenvolvimento das habilidades exigidas.

Quando olhamos para os documentos que regem o EQ no Ensino Médio, também vemos presente o fator histórico. Essa ideia, não tão recente no Brasil, também aparece em discussões de outros

\footnotetext{
8 Universidade Federal de Uberlândia (UFU), campus Pontal em Ituiutaba-MG.

9 Brasil. Ministério da Educação: Conselho Nacional de Educação/ Câmara de Educação Superior (CNE/CES), orgs. Diretrizes Nacionais para os Cursos de Química (Brasília, 2001), p. 2.

10 Ibid., 6.

11 Ibid., 2.
} 
currículos pelo mundo. Matthews ${ }^{12}$ nos apresenta discussões existentes já há algumas décadas em outros países, como Estados Unidos, Holanda, Dinamarca e os países da Grã-Bretanha. Tais currículos propunham uma incorporação mais ampla de temas de história, filosofia e sociologia da ciência na abordagem do programa e do ensino dos currículos de ciências. Assim, é defendida a ideia de aulas com uma abordagem mais contextualista nas aulas de ciências, ou seja, aulas onde as ciências "sejam ensinadas em seus diversos contextos: ético, social, histórico, filosófico e tecnológico"13, voltando à ideia de que as aulas de Ciência devam ser de e sobre Ciência.

\subsection{A Pesquisa em História da Ciência e Ensino de Química}

Um levantamento feito de forma livre em revistas, anais de eventos etc. revelou que pesquisas sobre uma interface entre $\mathrm{HC}$ e EQ já são comuns, assim como grupos de pesquisa na área já existem. Um exemplo disso é a existência desde 2010 da Revista Eletrônica História da Ciência e Ensino ${ }^{14}$, que surgiu a partir de diversas propostas em trabalhos, minicursos e apresentações de pesquisas das Jornadas de História da Ciência e Ensino que ocorrem na Pontifícia Universidade Católica de São Paulo15. Além disso, já existe em eventos de $E Q$ uma seção destinada a pesquisas na área.

Dentre as pesquisa encontradas, pode-se citar Martorano, Do Carmo e Marcondes ${ }^{16}$, que relatam uma experiência didática usando um documento histórico com descrições de estudos do cientista Ludwig F. Wilhelmy, que estudou a relação entre velocidade de reação e concentração com uma reação de inversão de sacarose, usando $\mathrm{HNO}_{3}$ como catalisador e aproveitando as diferentes polarizações da luz que cada isômero do açúcar causa. Barp ${ }^{17}$ também traz uma experiência com o uso de textos para efetivar uma contextualização histórica, abordando o tema radioatividade. Com isso, busca não apenas falar sobre radioatividade, mas trabalhar com concepções errôneas acerca da Ciência, como: "na Ciência há os

\footnotetext{
12 Michael R. Matthews. "História, Filosofia e Ensino de Ciências: A Tendência Atual de Reaproximação", trad. Cláudia M. de Andrade (Florianópolis: Caderno Catarinense de Ensino de Física, 1995).

13 Ibid., 3.

${ }^{14}$ Disponível no endereço https://revistas.pucsp.br/hcensino (Último acesso: julho de 2019)

15 Deividi M. Marques, "Dificuldades e possibilidades da utilização da História da Ciência no Ensino de Química: um estudo de caso com professores em formação inicial" (tese de doutorado, Universidade Estadual Paulista, Faculdade de Ciências, Bauru, 2010), p. 31-32.

${ }^{16}$ Simone A. A. Martorano, Miriam P. do Carmo \& Maria Eunice R. Marcondes, "A História da Ciência no Ensino de Química: o ensino e aprendizagem do tema cinética química", in Anais da IV Jornada de História da Ciência e Ensino: propostas, tendências e construção de interfaces (São Paulo, Brasil, 2013).

17 Ediana Barp, "Contribuições da História da Ciência para o Ensino da Química: Uma Proposta para Trabalhar o Tópico Radioatividade", in Anais do IV Jornada de História da Ciência e Ensino: propostas, tendências e construção de interfaces (São Paulo, Brasil, 2013).
} 
heróis que chegam à verdade e os vilões que erram o caminho"18, "os cientistas do passado não se enganavam e chegavam exatamente às ideias hoje aceitas"19 etc.

Ainda é possível citar alguns materiais para contribuir com os interessados na área. 0 livro História da Ciência para formação de professores ${ }^{20}$ auxilia professores e alunos em cursos de graduação em Química. Já para a educação básica, Freitas-Reis ${ }^{21}$ organiza várias sugestões de inserção de HC em aulas de Ensino Médio.

\subsection{A Formação de Professores de Química no contexto da História da Ciência}

Como já discutido, a formação de professores de Química no contexto da HQ ainda caminha a passos curtos, sendo que muitas vezes os licenciados que vão para as escolas nem ao menos tiveram uma formação que os dê confiança e meios para usá-la em seus planejamentos de aula. Marques mostra como ocorre essa formação e, principalmente, como ela ocorria nas últimas décadas ${ }^{22}$. 0 autor aponta que, por um bom tempo, os cursos de Química formavam profissionais com uma racionalidade técnica, com a perspectiva de se resolver vários problemas com o uso de técnicas, teorias e procedimentos baseados em métodos aprendidos em sua formação, porém sem percebem como as informações e os conhecimentos científicos chegaram até o conhecimento de quem o está usando. Isso era comum até 10 anos atrás, com um modelo de currículo onde o formando passava por uma etapa inicial recheada com as disciplinas específicas do curso e só após isso é que se deparava com disciplinas voltadas para formar o perfil docente.

Assim, formavam-se técnicos e não professores ${ }^{23}$. Em contrapartida, há necessidades formativas do professor de Química, como o conhecimento do conteúdo científico com uma formação reflexiva, sem esquecer que os saberes docentes são mais que uma simples soma entre conteúdo a ser ensinado e a prática pedagógica, mas um conjunto de saberes plurais, como saberes pessoais, saberes da formação escolar anteriores à formação docente, saberes da formação docente e saberes experienciais do seu trabalho cotidiano ${ }^{24}$.

\footnotetext{
18 Ibid, p. 16.

19 Ibid, p. 17.

20 Maria H. R. Beltran et al. História da Ciência para formação de professores (São Paulo: Livraria da Física, 2014)

21 Ivoní de Freitas-Reis, org. Estratégias para a Inserção da História da Ciência no Ensino: um compromisso com os conhecimentos básicos de Química (São Paulo: Livraria da Física, 2015)

22 Deividi M. Marques, "Dificuldades e possibilidades da utilização da História da Ciência no Ensino de Química: um estudo de caso com professores em formação inicial" (tese de doutorado, Universidade Estadual Paulista, Faculdade de Ciências, Bauru, 2010), p. 18-19.

23 Ibid., 20.

24 Ibid., 21.
} 
Acevedo-Días, García-Carmona e Aragão ${ }^{25}$ discutem a formação dos professores de Química na Espanha, em que se busca que os formandos tenham um bom entendimento da natureza da Ciência, usando da HC para isto. Eles buscam usar textos onde se exploram casos e controvérsias no processo de construção do conhecimento científico para que os licenciandos possam entender melhor o funcionamento próprio da Ciência. Os autores destacam que o uso da HC é fundamental na formação dos professores, apontando-a como o instrumento que permite mostrar os aspectos da natureza da Ciência e refletir sobre isto.

Marques mostra que os cursos não estão a ponto de alcançar uma formação satisfatória pela maneira como se aborda a HC nas graduações não ser feita de uma forma a mostrá-la corretamente. Várias pesquisas efetuadas no Brasil e em Portugal apontam que, mesmo após contato com alguma disciplina relacionada com a $\mathrm{HQ}$, muitos professores se mostram inseguros para usá-la como instrumento de ensino, embora reconheçam sua importância ${ }^{26}$. Também há o problema de, muitas vezes, os licenciandos manterem uma visão distorcida da HC. Assim, além do conteúdo a ser abordado é necessário pensar qual a concepção sobre a $\mathrm{HC}$ do formador responsável pela disciplina e qual a sua formação nessa área27. Além disso, 0 autor aponta outros problemas da formação docente, como visões distorcidas da natureza da Ciência. Uma de suas propostas é que as discussões sobre HC devam aparecer em mais de uma disciplina, tanto específicas quanto pedagógicas, em estágios e práticas de ensino.

\section{Metodologia}

O trabalho consistiu em uma pesquisa qualitativa com 11 alunos da disciplina História da Química, no Curso de Graduação em Química do campus Pontal da Universidade Federal de Uberlândia. A disciplina faz parte da grade curricular obrigatória da Licenciatura e da grade optativa do Bacharelado; por isso a pesquisa foi, em suma, com alunos da Licenciatura. A investigação se deu mediante questionários, atividades semanais e outras atividades realizadas durante a disciplina e propostas pela professora titular, que objetivavam levantar concepções dos alunos sobre como os assuntos discutidos em aula poderiam ser utilizados na educação básica.

Houve a aplicação de um questionário inicial para levantamento de concepções prévias dos alunos sobre a importância do uso da $\mathrm{HQ}$ no planejamento de aulas. A escolha pelo questionário como

\footnotetext{
25 José A. Acevedo-Díaz, Antonio García-Carmona \& María del Mar Aragão. "Historia de la ciencia para enseñar naturaleza de la ciencia: una estrategia para la formación inicial del profesorado de ciencia", Educación Química 28, (2017).

${ }^{26}$ Deividi M. Marques, "Dificuldades e possibilidades da utilização da História da Ciência no Ensino de Química: um estudo de caso com professores em formação inicial" (tese de doutorado, Universidade Estadual Paulista, Faculdade de Ciências, Bauru, 2010), p. 23.

27 Ibid., 107.
} 
instrumento de coleta de dados se deu pelas vantagens que este apresenta, como i) garantia de uniformidade nas respostas e, ii) ao participante da pesquisa, a oportunidade de tempo para formular suas respostas às questões propostas ${ }^{28}$. Para sua análise, optou-se por observar as respostas dos alunos, questão por questão, agrupando-as por semelhança.

As atividades semanais orientavam a busca em livros, artigos e sítios de internet sobre conhecimentos adquiridos/desenvolvidos por diferentes povos e diferentes épocas, sendo que as aulas tinham, como ponto de partida, a discussão das informações obtidas pelos alunos a cada semana, seguindo uma ordem (Quadro 1). Assim, buscou-se entender como os alunos proporiam aproveitar os conhecimentos adquiridos por certos povos em sala de aula.

Quadro 1: Povos abordados nas discussões de cada aula

\begin{tabular}{|c|c|}
\hline Aula & Povos \\
\hline $1^{a}$ & Pré-históricos \\
\hline $2^{\mathrm{a}}$ & Egípcios, Sumérios e Babilônios \\
\hline $3^{\mathrm{a}}$ & Persas, Chineses e Hindus \\
\hline $4^{\mathrm{a}}$ & Árabes \\
\hline $5^{\mathrm{a}}$ & Gregos \\
\hline $6^{\mathrm{a}}$ & Alquimia \\
\hline $7^{\mathrm{a}}$ & Séculos XVI e XVII \\
\hline $8^{\mathrm{a}}$ & Séculos XVIII e XIX \\
\hline
\end{tabular}

A discussão sobre cada um dos temas do quadro 1 priorizava os conhecimentos que detinham os povos, sua importância para a história e seu desenvolvimento, além de ponderar o quanto contribuiu para o avanço da Ciência como a conhecemos hoje e, por fim, como pode contribuir para aulas de Química na Educação Básica. Para fazer esse acompanhamento, os alunos entregavam as anotações das suas buscas ao final da aula - e já se informava o(s) povo(s) a ser(em) pesquisado(s) para a aula seguinte. Além disso, também houve observações diretas das discussões de todas as aulas. A observação direta dá um nível baixo de interferência nas atividades e normalmente neste tipo de pesquisa capta-se o comportamento natural dos alunos ${ }^{29}$.

Foram propostas outras duas atividades avaliativas da disciplina i) um seminário temático, abordando 0 aspecto histórico de alguns temas estudados na educação básica, e ii) produção de um plano de aula que tivesse uma abordagem de qualquer assunto da Química com o auxílio da HQ. Ambas as atividades foram desenvolvidas para o final da disciplina, após as várias semanas de discussões nas

${ }^{28}$ Chaer, Diniz e Ribeiro, "A Técnica do Questionário na Pesquisa Educacional", Revista Evidência 7, no 7 (2011): 9.

29 Ibid. 
aulas. Acredita-se que, com todas as atividades desenvolvidas, foi possível observar como os licenciandos passaram a encarar a HQ e sua importância para o EQ.

\section{Resultados e Discussões}

\subsection{A Ementa do Curso}

Observando o currículo do curso de Química citado percebe-se que há apenas uma disciplina de 30 horas intitulada História da Química. Os objetivos são: i) geral: Fornecer aos estudantes uma visão da Química na história da humanidade e de como, ao longo dessa história, seus conceitos se transformaram e ii) específico: Discutir com os alunos as grandes etapas na evolução do conhecimento científico, mostrando como essas se situam no momento socioeconômico e educacional, levando-os a refletir sobre a construção do conhecimento químico ao longo da história e suas implicações na prática educacional.

Comparando a descrição da ementa com o que os documentos trazem como necessários para um preparo dos licenciandos em $\mathrm{HQ}$, pode-se considerar que a ementa condiz com os pontos já destacados desses documentos e aparenta, de início, trazer uma capacitação satisfatória aos licenciandos. Porém, a disciplina em questão possui uma desvantagem, que é a carga horária insuficiente para realizar discussões aprofundadas em todos os tópicos.

\subsection{Das atividades realizadas com os alunos durante o semestre}

A principal forma de coleta de dados foi o acompanhamento da turma pelo pesquisador, como monitor, o que possibilitou a observação de tudo o que ocorria nas aulas.

\subsubsection{Questionário Inicial}

No primeiro dia de aula, os alunos responderam um questionário. As questões eram discursivas e referentes à disciplina em si: 1. Qual sua opinião sobre existir uma disciplina de história da química num curso de licenciatura em química? 2. Na sua opinião, qual a importância do ensino de história da química? 3. Como você acha possível relacionar história com a química? 4. O que você espera dessa disciplina? 5. Quais tópicos você gostaria de estudar?

A ideia foi obter um panorama inicial das ideias prévias do grupo. No tocante à relação História da Química x Ensino de Química, todos os alunos responderam, de alguma forma, que a disciplina é importante para o futuro professor de Química. Porém, grande parte defendeu uma importância da história pela história, isto é, que o simples fato de se conhecer a $\mathrm{HC}$, sua origem e como evoluiu é o importante, apenas para obter maior conhecimento. 
Na questão 1 muitos alunos citaram que é importante para conhecer os cientistas (também citados como "químicos" ou "pesquisadores") que contribuíram para o avanço da Química; uma aluna citou a importância da $\mathrm{HQ}$ para entender como a área da Ciência evoluiu desde seu surgimento; alguns alunos mencionaram a importância dos acontecimentos/ processos históricos que contribuíram para a formação e desenvolvimento da Química para compreender o que se tem hoje e, por fim, muitos citaram apenas que é importante aprender história e saber fatos do passado sobre a área. Observou-se a pouca relação que os alunos propõem entre a $\mathrm{HQ}$ e a prática docente, embora afirmem ser importante ter algum conhecimento disso para compreender a Química como ela é hoje. Notou-se a falta de eles, enquanto futuros professores, citarem alguma utilidade da $\mathrm{HQ}$ para o preparo de aulas ou até mesmo para discussões em sala de aula. Isso vai ao encontro das observações de Viana, Pereira e Oki30 e Callegario et al. ${ }^{31}$, que comentam que os licenciandos têm uma visão mais simplista da Química, o que justifica a necessidade de se inserir a História e Natureza da Ciência nas suas formações.

Percebe-se nas respostas à questão 2 uma miscelânea entre a visão que alunos que saem do Ensino Médio e entram na graduação geralmente carregam da Química com uma visão que já vai ao encontro do proposto por pesquisadores da área. Respostas como "para aumentar conhecimentos", "saber sobre cientistas e seus experimentos", "complementar o que se aprende na graduação", "saber do passado da ciência" vão ao encontro do dito por Viana, Pereira e Oki e Callegario et al. anteriormente comentado, porém nos deparamos surpreendentemente com respostas como "a partir da HQ passa-se a enxergar a Química não apenas como cálculos e fórmulas", "conhecer o legado da Química e ter uma visão mais ampla dos processos ocorridos para se chegar à ciência atual" e Enquanto "desmistificar alguns mitos (relacionados à ciência, como já comentado na seção 2.2. sobre o mostrado por Barp sobre usar a HQ para trabalhar com concepções errôneas sobre a ciência). Nas respostas a essa questão já vemos alguns respondentes trazendo ideias um pouco mais aprofundadas sobre o tema, ao contrário da questão anterior.

O que se observou na questão 3 foi a mesma importância da história pela história antes vista. Entretanto, acerca da relação entre história e Química, as respostas de parte da turma já foram um pouco mais aprofundadas, a exemplo do acontecido na questão 2. Alguns já viram importância em se considerar os diferentes contextos históricos onde os cientistas elaboraram os diferentes conhecimentos. Um dos alunos citou tal importância como um instrumento que pode proporcionar outra visão da Química aos estudantes, o que também casa com as observações feitas por Barp acerca das aulas com abordagem

\footnotetext{
30 Hélio E. B. Viana, Letícia S. Pereira \& Maria do Carmo C. Oki. "A História da Química como disciplina de Graduação: Levantamento de concepções de graduandos do IQ/UFBA", in Anais, III Jornada de História da Ciência e Ensino: Propostas, Tendências e Construção de Interfaces (São Paulo, Brasil, 2011).

${ }^{31}$ L. J. Callegario et al. "História da Ciência no Ensino de Química: Uma Revisão", Revista Virtual de Química 7, no 3 (2015).
} 
históricas ajudarem na compreensão da natureza da Ciência; porém, alguns alunos trazem respostas parecidas com as questões anteriores, como fatos importantes para a Ciência, citar descobertas, teorias e nomes de cientistas que contribuíram com a Química, o que vai ao encontro das considerações de Callegario et. al. sobre a visão mais simplista acerca da HC apresentada por licenciandos.

$\mathrm{Na}$ questão 4, nove alunos comentaram que, com a disciplina, eles poderiam aprofundar mais no conhecimento da Química, entender como começou e como ela chegou a ser como é hoje. Um desses e os outros dois esperavam também conhecer mais sobre cientistas, sendo que um deles citou como importante saber se houve a participação de brasileiros neste avanço da Ciência. Pode-se dizer que a visão dos alunos, embora tenham mostrado um pouco da compreensão da importância dos momentos históricos nas questões anteriores, ainda focaram, em parte, nos conteúdos e em cientistas.

Barp32 nos mostra que os alunos com quem trabalhou no Ensino Médio possuem visão parecida. Sobre a própria Ciência, os alunos mostram concepções alternativas, como enxergarem a Química como uma Ciência pronta ou como verdade absoluta e valorizarem a questão dos pais (pai da Química, pai da Física), ênfase na descoberta, desconsiderando outros personagens que contribuíram para tal. A autora cita que a abordagem histórica para um assunto em específico - a radioatividade - mostrou também aos alunos que os conhecimentos científicos não são mérito de uma mente especial, mas um processo de construção de conhecimento que passa por várias etapas e pessoas diferentes, sendo que o momento vivido pode influenciar na continuidade ou não de pesquisas.

Por fim, na última questão, todos os alunos apenas citaram algum conceito ou alguma "curiosidade", sendo que ninguém relacionou a disciplina com outras já vistas ao longo do curso, ou com seu futuro como profissional. A lista de tópicos citados se limitou a: Principais descobertas, Alquimia, Principais Químicos, Experimentos Importantes, Início da Química, Modelos Atômicos, Radioatividade, Tabela Periódica e Elementos Químicos.

\subsubsection{Atividades Semanais}

Durante as semanas os alunos levantavam informações sobre algum povo ou grupo de povos (Quadro 1), focando nos conhecimentos que detinham, sua importância para a história e desenvolvimento desses povos, o quanto isso contribuiu para o avanço da Ciência como conhecemos hoje e, por fim, como isso pode contribuir para aulas de Química de ensino médio.

Durante as aulas eram mobilizadas discussões complementares, como a relação que determinados conhecimentos tinham com outros aspectos das vidas dos diferentes povos, como crenças,

\footnotetext{
32 Ediana Barp, "Contribuições da História da Ciência para o Ensino da Química: Uma Proposta para Trabalhar o Tópico Radioatividade", in Anais do IV Jornada de História da Ciência e Ensino: propostas, tendências e construção de interfaces (São Paulo, Brasil, 2013).
} 
culturas, política, necessidades, região em que viviam etc. Depois da quarta aula, a professora pedia aos alunos que planejassem como poderiam usar os conhecimentos obtidos até então nas aulas de Química. A maioria optou por conhecimentos científicos do passado aos dias atuais. Uma aluna propôs elaborar uma aula com curiosidades e dois sugeriram abordar a evolução da Química e da Medicina dos tempos antigos aos dias atuais.

Estas atividades foram úteis para os alunos por proporcionarem aos alunos momentos para perceberem que os conhecimentos que hoje vemos em estudos de Química são fruto de atividades, conhecimentos adquiridos e produzidos por muitos povos em diferentes épocas e culturas, levando-os a entender que a ciência que conhecemos hoje não é algo pronto e acabado, mas um conhecimento algo sempre passivel de mudanças. Entretanto, como visto nas propostas de uso em elaboração de aulas, os alunos ainda se apegavam neste ponto à visão mais simplista do uso da $\mathrm{HQ}$, se limitando a aulas de curiosidades ou comparações.

\subsubsection{Seminários}

Como uma das atividades, a turma foi dividida em 4 grupos, cada um com um tema: modelos atômicos, equilíbrio químico, tabela periódica e eletroquímica, que são temas normalmente abordados nas aulas do ensino médio. Em cada seminário, deveriam apresentar: i) desenvolvimento histórico do tema escolhido; ii) se teve influência do período histórico onde começou a se estudar sobre o tema, ou se o estudo influenciou a humanidade de alguma forma e iii) Qual a importância de se ver isso nas aulas de ensino médio.

Um dos objetivos da atividade tanto para a pesquisa quanto para a disciplina foi comparar as concepções dos alunos levantadas inicialmente pelos questionários com o que eles discutiram durante 0 semestre. $O$ quadro abaixo contém as observações anotadas no diário de bordo do pesquisador acerca de cada trabalho:

Quadro 2: observações sobre cada seminário

\begin{tabular}{|c|c|}
\hline Tema & Observações \\
\hline Modelos Atômicos & $\begin{array}{l}\text { Trouxeram uma exposição dos diferentes modelos atômicos de forma } \\
\text { semelhante ao que ocorre tradicionalmente nas aulas de ensino médio: } \\
\text { mostrando os modelos um por um, de Leucipo e Demócrito até o modelo } \\
\text { quântico; } \\
\text { Destacaram apenas a ordem em que aparece cada modelo; } \\
\text { Parece não ter ocorrido uma mudança significativa na forma como viam a HQ no }\end{array}$ \\
\hline
\end{tabular}




\begin{tabular}{|c|c|}
\hline & $\begin{array}{l}\text { começo da disciplina e como passaram a ver nesta etapa da disciplina (ainda } \\
\text { enxergam } \mathrm{HQ} \text { de forma muito simplista). }\end{array}$ \\
\hline Tabela Periódica & $\begin{array}{l}\text { Evolução dos agrupamentos e representações dos elementos por alguma } \\
\text { semelhança entre eles; } \\
\text { Apesar de o trabalho aparecer dividido por nomes de cientistas ou leis de } \\
\text { agrupamentos (tríades ou lei das oitavas, por exemplo), o foco estava nos } \\
\text { agrupamentos dos elementos, o que mostra uma leve mudança na concepção } \\
\text { do grupo com relação à HQ: o foco dos alunos saiu do cientista e passou para o } \\
\text { conhecimento; } \\
\text { Ao mostrar a forma como cada cientista tentou agrupar, pôde-se notar que } \\
\text { pessoas diferentes com gostos diferentes podem ser influenciadas por esses } \\
\text { gostos para seus trabalhos; } \\
\text { Ao mostrar as tentativas de agrupamento, primeiro a partir de massas atômicas, } \\
\text { depois volume atômico até chegar ao número atômico, foi possível observar } \\
\text { duas coisas: i) que os elementos possuem propriedades relacionadas à sua } \\
\text { quantidade de elétrons totais e por camadas, tamanho dos átomos/íons etc. e } \\
\text { que alguns elementos se comportam de forma parecida por compartilharem } \\
\text { algumas dessas propriedades e ii) que dá para se observar essas propriedades } \\
\text { por meio da tabela periódica, o que poderiam muito bem ser aproveitadas nas } \\
\text { aulas de Química do ensino médio. }\end{array}$ \\
\hline Eletroquímica & $\begin{array}{l}\text { Trouxeram uma abordagem do tema a partir do estudo de dois cientistas, } \\
\text { Galvani e Volta, prosseguindo com a evolução do tema, passando por outros } \\
\text { cientistas, como Daniell; } \\
\text { Não puseram o foco só nos cientistas, olhando para seus estudos; } \\
\text { Em sua abordagem apontaram diferenças nos estudos de Galvani e Volta, o que } \\
\text { mostra a evolução de um conceito passando por mais de uma pessoa e sendo } \\
\text { uma construção, não algo acabado; } \\
\text { Foi possível observar um avanço entre como eles viam a HQ no começo da } \\
\text { disciplina e como veem neste ponto. }\end{array}$ \\
\hline Equilíbrio Químico & $\begin{array}{l}\text { Optaram por trabalhar em torno de alguns cientistas considerados os principais } \\
\text { nomes no desenvolvimento do conceito - Berthollet, Le Chatelier e Haber; } \\
\text { Não se limitaram a focar só nos cientistas; antes, o foco do seminário foi na } \\
\text { construção do conceito em si, destacando nomes importantes junto dos seus }\end{array}$ \\
\hline
\end{tabular}


contextos históricos e sociais;

Destacaram a relação entre Ciência e as necessidades da época; entre Ciência e Política e entre vários estudos de uma época;

Procuraram discutir a construção do conceito como algo em construção, não algo acabado; uma contribuição não apenas no conceito em si para as aulas de Química do ensino médio, mas também para a própria visão que os alunos têm de Ciência;

Pela forma como este grupo apresentou o seminário, pode-se considerar que houve um avanço entre como eles viam a $\mathrm{HQ}$ no começo da disciplina e como veem neste ponto.

\subsubsection{Planos de Aula}

A última atividade realizada foi um plano de ensino para 3 a 4 aulas, com tema livre. 0 objetivo era identificar como eles utilizariam a $\mathrm{HQ}$ em suas aulas. A relação dos temas escolhidos e dos usos da $H Q$ aparece na Tabela a seguir.

Tabela 1: Elaboração dos planos de aula: temas escolhidos e como usar a História da Química

\begin{tabular}{|c|c|c|}
\hline Temas & Uso da História da Química & $\mathbf{n}^{\mathbf{0}}$ de citações \\
\hline Equilíbrio Químico & Início da matéria & 2 \\
\hline Equilíbrio Químico & Nenhum citado & 1 \\
\hline Termoquímica & Início da matéria & 1 \\
\hline Eletroquímica & Início da matéria & 1 \\
\hline Ácido-base & Nenhum citado & 1 \\
\hline Química Orgânica & Durante o desenvolvimento das aulas & 1 \\
\hline
\end{tabular}

Apesar de na atividade anterior os alunos terem apresentado sugestões mais elaboradas para inserir a $\mathrm{HQ}$ nas aulas, nesta atividade, na qual os alunos tiveram a liberdade de elaborar seu plano de aula, pouco se viu dessa inserção. Além disso, nem todos os alunos entregaram essa atividade.

Pode-se presumir disto que, mesmo após cursar uma disciplina de História da Química, ainda assim os licenciandos não se sentem preparados ou interessados para usar este tipo de conhecimento em 
suas aulas. Assim, a afirmação de Callegario et. al. ${ }^{33}$ de que há uma necessidade de se inserir a História e Natureza da Ciência na formação dos professores pode indicar que a disciplina do jeito que é estruturada ainda não oferece base suficiente para o licenciando mudar algumas concepções arraigadas e perceber a própria Química por outras perspectivas.

\section{Considerações Finais}

No presente trabalho foram observadas aulas de $\mathrm{HQ}$ durante todo um semestre, de modo a procurar saber se a disciplina ofertada oferece capacitação para os alunos se sentirem capazes de inserir a $\mathrm{HQ}$ em seus planejamentos e se, ao longo da disciplina em questão, eles passaram a dar mais importância à influência do contexto histórico tanto na docência, quanto para sua formação pessoal. A partir deste trabalho, pode-se observar que:

$1^{\circ}$ Durante o semestre, observando a participação dos alunos nas discussões das aulas do início ao fim do semestre e fazendo um comparativo da visão dos alunos sobre a $\mathrm{HQ}$ entre o mostrado no questionário inicial e o mostrado nos seminários a maioria dos alunos da disciplina passou a ver uma importância da $\mathrm{HQ}$ enquanto ferramenta para $0 \mathrm{EQ}$, tanto para fugir das "aulas tradicionais" quanto para as aulas proporcionarem discussões mais aprofundadas, ajudarem os alunos a terem uma visão mais crítica da Ciência e maior compreensão da sua natureza e da forma como se faz Ciência;

$2^{\circ}$ Os próprios alunos da disciplina, salvo poucas exceções e cada um à sua maneira, passaram a ter uma visão mais madura e crítica da Química. Passaram a compreender melhor como se faz Ciência, passaram a enxergá-la como algo em constante construção, sujeita sempre a erros e acertos e passaram a entender que ela não é uma atividade que surge à parte da sociedade, mas que sofre influências dos contextos histórico, político e social aos quais os cientistas estão incluídos - e que influencia também essa sociedade da qual os cientistas fazem parte;

$3^{0}$ Ainda é preciso repensar a preparação dos futuros professores para usar essa ferramenta, uma vez que os alunos mostraram, a partir das suas últimas atividades, que mesmo tendo adquirido uma compreensão maior sobre a $\mathrm{HQ}$, ainda não se sentem capacitados para usá-la em seus planejamentos de aula.

Vale ressaltar a importância de trabalhos como este para repensar o alcance de determinadas estruturas curriculares em formar profissionais capacitados, a importância das disciplinas do curso e, neste caso em específico, repensar os avanços e limitações na à preparação dos futuros professores para usarem a $\mathrm{HQ}$ como ferramenta para o ensino. Também se pode destacar que este trabalho aponta a importância da $\mathrm{HQ}$ nos cursos formação de professores, não só para estarem mais aptos para sua atividade profissional, mas também para se pensar nas contribuições à formação do licenciando.

${ }^{33}$ L. J. Callegario et al. "História da Ciência no Ensino de Química: Uma Revisão", Revista Virtual de Química 7, no 3 (2015): 14. 
Para futuras pesquisas na área, seria interessante aprofundar o conhecimento sobre a capacidade de se preparar profissionais da disciplina por um período de tempo maior, observando mais turmas por alguns anos. Também poderia ser elaborado um panorama abrangendo mais turmas de mais universidades, avaliando alunos e disciplinas de diferentes regiões. Por fim, também seria importante conhecer mais sobre os professores das disciplinas de $\mathrm{HQ}$ pelo país.

\section{SOBRE OS AUTORES:}

lago Ferreira Espir

Universidade Federal de Uberlândia

agoespirsnt@hotmail.com

Alexandra Epoglou

Universidade Federal de Sergipe, São Cristóvão

epoglou@gmail.com

Deividi Marcio Marques

Universidade Federal de Uberlândia

deividi@ufu.br 